\section{Declaración Pública de la Sociedad Chilena de Infectología respecto de la modificación del esquema de prevención de la enfermedad meningocóccica}

\author{
Public statement of the Chilean Infectious Diseases Society about changes to the \\ national schedule of vaccination against meningococcal disease
}

Recientemente el Ministerio de Salud ha dispuesto mediante el Decreto exento $\mathrm{N}^{\circ} 1.201$ del 22-11-2013 que, a partir del 1 de enero de 2014 será obligatoria la vacunación contra enfermedad meningocóccica (EM) para toda la población infantil, al cumplir 12 meses de edad, con vacuna conjugada tetravalente, la que se administrará en esquema de una sola dosis al año de vida.

Esta medida viene a reemplazar el actual esquema de vacunación, iniciado a fines del 2012 en el contexto del manejo de brote de EM, para niños entre 9 meses de edad y menores de 5 años, que utiliza una vacuna antimeningocóccica conjugada A C W Y en esquema de una ó dos dosis dependiendo de la edad.

Frente a esta decisión y considerando la dinámica de presentación que ha tenido el brote de EM, en el que predomina un serogrupo emergente (W135-ahora denominado $\mathrm{W})$, y sumado al reciente registro en nuestro país de una vacuna para ser administrada a partir de los 2 meses de edad, esta Sociedad manifiesta su desacuerdo con lo dispuesto por la autoridad sanitaria. Nuestros fundamentos derivan del análisis epidemiológico que ha caracterizado a esta enfermedad:

- Un sostenido aumento del número de casos, lo que es propio de este tipo de brotes. Hasta la semana epidemiológica 50 del año 2013 se han notificado 113 casos de EM causadas por el serogrupo W, representando un aumento de $19,6 \%$ respecto al mismo período del año 2012 (97 casos).

- Los pacientes bajo 5 años de edad corresponden al 33\% del total de casos (n: 44). De estos, dos tercios tienen bajo 9 meses de edad, grupo etario que no recibirá vacuna de acuerdo a la nueva medida de control de brote.

- El número de casos reportados en adultos también resulta muy preocupante. El grupo etario sobre los 40 años acumula aproximadamente el $49 \%$ de los casos. Los adultos de 65 años y más dan cuenta de $11,3 \%$ y $8,3 \%$ corresponden al grupo entre 55 y 59 años, con tasas de incidencia de $0,87 / 100.000$ habs. y $1,14 / 100.000$ habs. respectivamente.

- El 65,1\% de los casos de EM por serogrupo W han sido notificados en la Región Metropolitana, principal región afectada.

- La letalidad para la EM por serogrupo W continua siendo elevada (23\%).

Con la nueva disposición ministerial, que desplaza la vacuna anti-meningocóccica conjugada tetravalente al año de vida, se dejará sin cobertura a un grupo de niños que estaba siendo protegido (niños de 9 meses y más) y que claramente son un grupo de riesgo para EM.

Más aún, la nueva disposición ministerial no considera expandir la vacunación a niños a partir de los 2 meses (importante grupo de riesgo) a pesar de que el Instituto de Salud Pública de Chile recientemente ha autorizado el uso de una vacuna anti-meningocóccica conjugada tetravalente a partir de esa edad.

En base a estos antecedentes, la Sociedad Chilena de Infectología recomienda analizar la incorporación de vacuna anti-meningocóccica a partir de los 2 meses de edad, en un esquema de dos o tres dosis ya que es la mejor manera de proteger a un grupo altamente vulnerable.

Además, y de acuerdo con las características epidemiológicas y persistencia de circulación de Neisseria meningitidis en nuestro país, no será posible el control del actual brote si no se considera el expandir la vacunación a otros grupos etarios, estrategia que debiera ser considerada.

Alma Muñoz, Lily Contreras, Marcela Potin,
Jaime Cerda, Isabel Domínguez,
Alberto Fica y Liliana Véliz
Comité Consultivo de Inmunizaciones
Sociedad Chilena de Infectología

Santiago, diciembre de 2013
Potenciales conflictos de interés Alma Muñoz: ha recibido financiamiento de la industria farmacéutica por concepto de estudios clínicos (GlaxoSmithKline, Sanofi Pasteur, Novartis, Pfizer Inc.), charlas (Pfizer Inc., Sanofi Pasteur), asistencia a congresos (GlaxoSmithKline, Sanofi Pasteur, Berna, Novartis), asesoría de expertos (GlaxoSmithKline). Participación como investigador principal en estudio relacionado con vacuna Men B en adolescentes chilenos (Novartis) y co investigador en estudio de vacunas meningocóccica polisacárida/ conjugada en niños chilenos de 2-10 años de edad (Sanofi Pasteur) Lily Contreras: ha recibido

financiamiento de la industria farmacéutica por concepto de asistencia a Congresos de Infectología nacionales por parte de Sanofi Pasteur, GlaxoSmithKline, y Merck-Chile.

Marcela Potin: ha recibido financiamiento de la industria farmacéutica por concepto de charlas sobre enfermedad meningocóccica y vacunas del Laboratorio Sanofi Pasteur. Liliana Veliz: ha recibido financiamiento de la industria farmacéutica por concepto de charla en Taller "Encuentro de vacunatorios" auspiciado por Merck-Chile.

Isabel Domínguez ha recibido financiamiento de la industria farmacéutica por concepto de charlas sobre vacuna antineumocóccica financiadas por Pfizer Inc.

Alberto Fica y Jaime Cerda declaran no tener potenciales conflictos de interés.

Recibido: 30 de diciembre de 2013

Correspondencia a: Jeannette Dabanch P. sochinf@sochinf.cl 